\title{
Reconditioning in synchronous operation with one parallel induction generator
}

\author{
Alana S. Magalhães ${ }^{1,2}$, Pedro H. F. Moraes ${ }^{1}$, Alan H. F. Silva ${ }^{1,2}$, Pedro H. G. Gomes ${ }^{1,2}$, Aylton J. \\ Alves $^{1}$, Wesley P. Calixto ${ }^{1,2}$.
}

\begin{abstract}
The purpose of this paper is to compare mathematical modeling and practical bench in order to validate the electrical interactions between an induction generator and a synchronous generator. Two generators was connected to a common bus in steady state, subject to non-linear load. The results comparing modeling and bench tests show that the induction generator besides the active power increasing, has a better way for harmonic currents flowing in common bus. It was concluded that the induction generator repowering and attenuates current harmonic components present at the connection point, improving the network voltage profile.
\end{abstract}

Index Terms-Repowering, Induction Generator, Synchronous Generator, Harmonics.

\section{INTRODUCTION}

$\mathrm{R}$ epowering hydroelectric power plants has been increasing the power generated. Since there is spare capacity of turbine power and that is not being exploited by the generator already installed, it can be repowered. There are three possible ways to repowering: i) replacing the synchronous generator for a bigger one; ii) adding a second synchronous generator through double coupling on the turbine shaft; iii) adding a second generator coupled to the turbine shaft, but in this case an induction generator.

The induction generator is a viable technical and economical option to power generation [1]. The induction generator is used in electrical power plants repowering therefore has a low cost, is more robust, has simple construction, lower cost and less maintenance when compared to a synchronous machine. As disadvantage, external resources are required to compensate reactive power. On repowering, smaller induction generator is connected on a common bus to a larger synchronous generator and thus induction generator may have its reactive power compensated

A. S. Magalhães $\{1,2\}$, alanadsm@gmail.com

L. C. A. Junior $\{1\}$, leovir.engmecatronica@gmail.com

C. A. Matias $\{1\}$, calebeabrenhosa@gmail.com

A. H. F. Silva $\{1,2\}$, alanhfs@gmail.com

E. G. Domingues $\{1\}$, eldergd@ifgoias.edu.br

A. J. Alves $\{1\}$, aylton.alves@ifg.edu.br

W. P. Calixto $\{1,2\}$, wpcalixto@ieee.org

1Experimental and Technological Research and Study Group (NExT), Federal Institute of Goias (IFG), Goiânia, Brazil.

2 School of Electrical, Mechanical and Computer Engineering, Federal University of Goias (UFG), Goiânia Brasil.\} by synchronous generator, without power factor losses in the coupling point between them and can be dispensed of the control voltage, as this will be determined by system [2].

The induction generator besides low maintenance, does not require DC excitation and synchronization. In machines parallel operation is necessary to use of motorized thermomagnetic circuit breakers and in the case of induction generators, where the synchronization is not required, it reduces the cost of the circuit breaker [3]. In the distribution system the impact of induction generators connection is studied in [4]. To stabilize reactive field, the induction generator needs to reactive power on system input. The system supplies this reactive power, affecting losses and system voltage drops. The results show the relationship between losses due to change of the voltage profile, and as a solution indicates the power factor correction. The Hydro-Quebec system in Canada, the demand for small generators connection is increased [5].

Recently, study [6] shows that rural electrification can be supplied by small hydropower through induction generator and intelligent controllers in more economic schemes and cost-effective options. Studies in [7] compares the use of conventional synchronous machines together with the static frequency converter (SFC) in the Kadamparai plant with substitution by a variable speed induction generators to utilize the grid load variation effectively. The results show that the plant can be operated by variable speed machines.

The parallel operation voltage and frequency control was performed in [8], where induction generator can provide constant power and does not have excitation control. The synchronous generator has variable excitation in different load conditions. The results also show that changing the reactive load consumption can be supplied by the synchronous generator, keeping the voltage constant to $1 \mathrm{pu}$. The induction generator operates at full rating and does not respond does not respond to load change in the consumer.

In the interconnected electric power system IEPS there is presence of a large number of synchronous generating units of high power and non-linear loads. The application of rules aiming to limit the harmonic content of tensions on possible values of maintaining acceptable power quality is recommended [9]. In [10] is presented tests that induction generator does not introduce harmonics in power system. [11] shows the repowering system using the common bus two machines of the same power, a synchronous generator and an 
induction generator. The results show that the induction generator reduces harmonic content in the common bus.

In [13] proposed the development of a simulation model for repowering steam plant, providing dark areas of links aimed at accelerating the power system restoration process services.

Recently, [14] conduct a study to evaluate the economic and repowering prospects of a plant into disuse in the territory of Petralia Sottana (Sicily). The work shows that the refurbishment of the plant "Catarrate" contributes to the energy independence of the local community, with an estimated annual production of renewable energy of approximately $220 \mathrm{MWh}$ and at the same time, the preservation of industrial heritage.

This paper aims to repowering the system. Furthermore, the objective is that the induction generator insertion in the common bus to a synchronous generator, can improve the sinusoidal profile of voltage and current. Thus, it is noted that the induction generator is still a preferential path for harmonic currents becoming protection synchronous generator, which is a more expensive and less robust machine that induction one.

\section{MATHEMATICAL MODELING}

\section{A. Three-Phase Induction Generator under Non-Sinusoidal Steady State}

Fig. 1 presents electrical circuit that models the induction machine in non-sinusoidal steady state, where $X_{E}$ is stator leakage reactance and $E_{a h}$ is the $h$ order harmonic component of voltage, induced in Phase $a$ machine stator, by the magnetic field produced by sinusoidal spatial distribution of rotating magneto-motive force of $h$ order, $\mathrm{fmm}_{\mathrm{E} 0 h}$ [12].

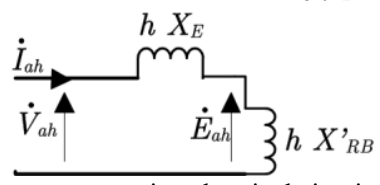

Fig. 1. Induction machine representative electrical circuit.

Considering odd values for $h$ index, which are most likely harmonic components produced by non-linear loads, one can write:

$\dot{V}_{h}=\dot{Z}_{h} \cdot \dot{I}_{h}$

With such assumptions the equivalent circuit becomes purely inductive, and impedance $\dot{Z}_{h}$ of the circuit is expressed by:

$\dot{Z}_{h}=j h\left(X_{E}+k_{R} \cdot X_{R B}^{\prime}\right)$

As $X_{R B}^{\prime}$ has very similar value to $X_{E}$ and $k_{R}$ tends to one, can be a approach to accept $\dot{Z}_{h}$ to:

$\dot{Z}_{h} \cong j 2 h X_{E}$

Therefore, (1), (2) and (3), leads to:

$\dot{V}_{h} \cong j 2 h X_{E} \dot{I}_{h}$

\section{B. Three-Phase Synchronous Generator under Non- Sinusoidal Steady State}

For all phases of synchronous machine, and adopting usual nomenclature to represent harmonic reactance proposed in [12], we have (5) where $r_{E}$ is per phase stator resistance, $X_{S}$ is synchronous reactance at frequency $\omega$ and $X_{a f}$ is stator-rotor mutual reactance at frequency $\omega$.
$\dot{V}_{h}=\left[r_{E}+j h X_{S}\right] \cdot \dot{I}_{h}+j \frac{h X_{a f}}{2} \cdot \dot{I}_{f(h)}$

In practice $r_{E} \ll X_{S}$ and representing the last term by (6), leads to (7):

$\dot{E}_{h}=j \frac{h X_{a f}}{2} \cdot \dot{I}_{f_{h}}$

$\dot{V}_{h} \cong j h X_{S} \dot{I}_{h}+\dot{E}_{h}$

Expression (7) suggests the circuit of Fig. 2.

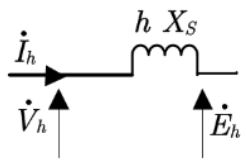

Fig. 2. Cylindrical rotor synchronous machine equivalent circuit.

From undertaken mathematical and physical analyzes, it is concluded that power flowing through terminals $\dot{E}_{h}$ is practically inductive reactive, therefore suggesting, there is only inductive impedance in circuit which relates $\dot{V}_{h}$ and $\dot{I}_{h}$, which may be represented by $h X_{S}$.

\section{Association between Induction and Synchronous Generator}

Assuming two machines, one synchronous and other an induction one, of same power, connected to same bus, Fig. 3, it is possible to make comparative analysis of harmonic current components in both.

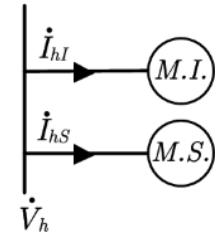

Fig. 3. Parallel machines.

Expressions (4), induction machine and (7), synchronous machine, can be rewritten as illustration of Fig. 3, and (8) and (9), respectively.

$\dot{V}_{h} \cong j 2 h X_{E} \dot{I}_{h I}$

$\dot{V}_{h} \cong j h\left(X_{S}+X\right) \dot{I}_{h S}$

Where $X$ is equivalent reactance between terminals $\dot{E}_{h}$. Substituting (8) in (9) and through algebraic manipulation, it has:

$\frac{\dot{I}_{h I}}{\dot{I}_{h S}}=\frac{X_{S}+X}{2 \cdot X_{E}}$

Assuming threshold condition, where $X$ is is negligible in comparison to $X_{S}$ and $X_{S}=10 \cdot X_{E}$, from (10) we have:

$\frac{\dot{I}_{h I}}{\dot{I}_{h S}}=5$

In expression (11) $X_{S}$ represents phase leakage reactance of the synchronous machine, plus armature reaction, while $X_{E}$ is stator leakage reactance of induction machine. By boundary condition, it is possible to ensure the inequality:

$\dot{I}_{h I}>5 \cdot \dot{I}_{h S}$

In (12) it is conclude that in same bus, harmonic components of currents will flow with higher intensity to induction machine. This fact justifies the proposal of this work, of using induction machine as a means to absorb harmonic components of currents, attenuating its flow to synchronous machine. It follows that when the machine is seen only by the fundamental sinusoidal component, the power flowing in the rotor is almost exclusively active, while, 
when viewed for a single harmonic component, the power flowing in the rotor is almost entirely inductive reactive. It allows to assume the intensities as irrelevant, or even the direction of electromagnetic torque (motor or generator), to simulate the conditions of harmonic mitigation in synchronous machine.

\section{METHODOLOGY}

The methodology will be developed in following steps:

i. Modeling the illustrated electrical system in Fig. 4 with the characteristics Tab. I;

ii. Conducting testing connected to common bus nonlinear load $N_{L}$;

iii. Conducting testing connected to common bus nonlinear load $N_{L}$ and synchronous generator $S_{G}$;

iv. Conducting testing connected to common bus nonlinear load $N_{L}$, synchronous generator $S_{G}$ and an induction generator $I_{G}$.

v. Conducting testing connected to common bus nonlinear load $N_{L}$ and an induction generator $I_{G}$.

The power values will be recorded in meter $M_{1}$ in order to prove the increase in power output. For more information on harmonics attenuation, the harmonic content will be recorded at the point of measurement $M_{1}, M_{2}, M_{3}$ and $M_{4}$ to have better understanding of harmonic flows in the system.

\section{A. Connection Machine and Loads for Case Study 1}

Laboratory tests will be carried out, for IEPS shown in Fig. 4, where $M_{1}, M_{2}, M_{3}, M_{4}$ and $M_{5}$ are points for quantities measurements.

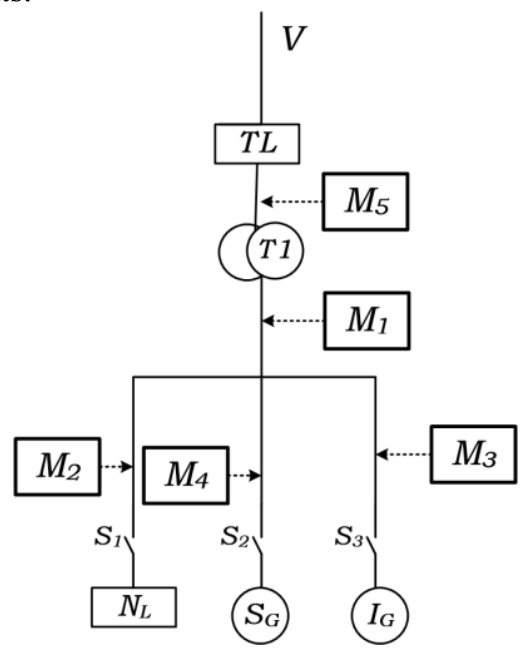

Fig. 4. Interconnected electrical power system - IEPS for Case Study 1.

Experimental tests of this work were performed in the laboratory with a system composed of two generating units, a synchronous and another induction. Both units are in parallel by feeding the first rectifier which constitute the nonlinear load. The $N_{L}$ load is a resistive load of 500 watts, fed by a rectifier. To regulate properly the speed of generators, $S_{G}$ and $I_{G}$, they used DC motors.

The Fig. 5 presents the equipment used in the laboratory.

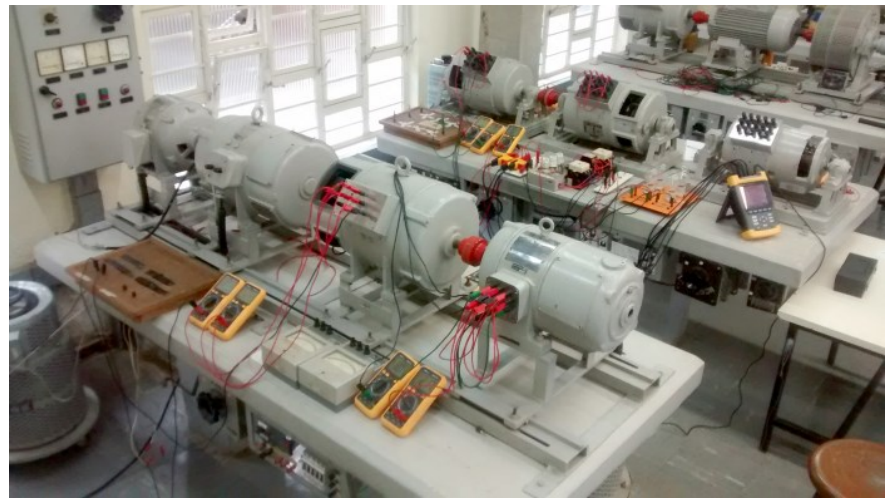

Fig. 5. Equipments utilized in laboratory tests.

\section{B. Connection Machine and Loads for Case Study 2}

Laboratory tests will be carried out, for IEPS shown in Fig. 6, where $M_{1}, M_{2}, M_{3}$ and $M_{4}$ are points for quantities measurements.

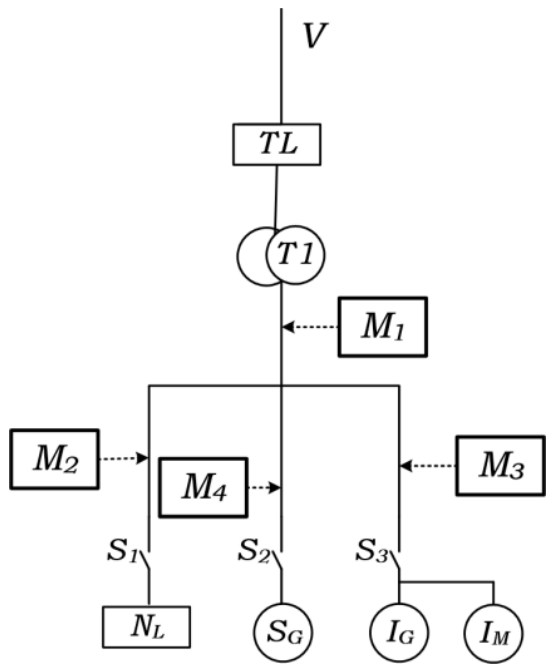

Fig. 6. Interconnected electrical power system - IEPS for Case Study 2.

Experimental tests of this work will be performed in the laboratory with system composed of two generating units, a synchronous and another induction. Both units will be in parallel by feeding nonlinear load $N_{L}$ consisting of triac rectifier feeding sets of lamps. Two phases with total power of $5 \mathrm{~kW}$ and the third phase with $4 \mathrm{~kW}$. To regulate generators speed, $S_{G}$ and $I_{G}$. were used diesel engine and induction motor with frequency inverter, respectively. Since the induction motor will be fed by the common bus, through $S_{3}$ key.

The Fig. 7 presents the equipment used in the laboratory, in which Fig. 7(a) the induction generator and Fig. 7(b) shows the synchronous generator.

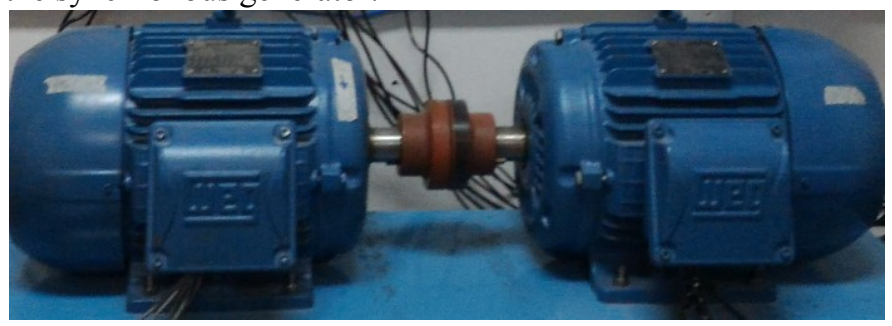

(a) Induction Generator 


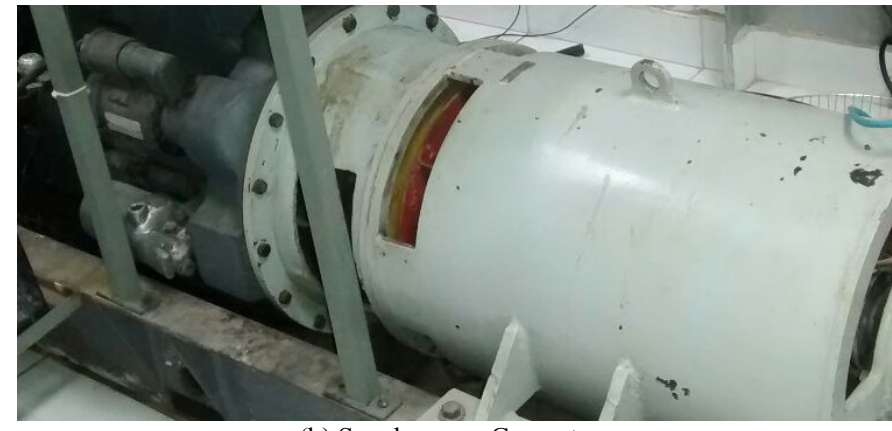

(b) Synchronous Generator

Fig. 7. Equipments utilized in laboratory tests.

IV. RESULTS

\section{A. Case Study 1}

\section{1) Experimental Tests}

Components and values of IEPS of Fig. 4 are reported in the Tab. I, along with their values.

Table I. Acronyms and Values of the Components from IEPS.

\begin{tabular}{c|l|l}
\hline Variable & Components & Components Values of Used \\
\hline$S_{G}$ & $\begin{array}{l}\text { Synchronous Generator } \\
\text { (main generator) }\end{array}$ & $\begin{array}{l}\text { 2kVA, 230V, three-phase, salient, } \\
4 \text { poles, 60Hz }\end{array}$ \\
$I_{G}$ & Induction Generator & $2 \mathrm{kVA}, 220 \mathrm{~V}$, three-phase, cage \\
& & rotor, 4poles, $60 \mathrm{~Hz}$ \\
$N_{L}$ & Nonlinear Load & $500 \mathrm{~W}$ three-phase, $380 \mathrm{~V}, 60 \mathrm{~Hz}$ \\
$T_{1}$ & Transformador & $5 \mathrm{~kW}, 380 / 220 \mathrm{~V}, \Delta / \mathrm{Y}$ aterrado \\
$S_{1}, S_{2}, S_{3}$ & Interrupter & \\
\hline
\end{tabular}

The main objective of IEPS experimental testes is to obtain the increment of power generated plant at the measurement point $M_{1}$ and results of total harmonic distortion of current $T H D_{i}$, measured in points $M_{1}, M_{2}, M_{3}$ and $M_{4}$, maintaining total harmonic distortion of voltage $T H D_{v}$ within standard limits.

The limit established by standard and presented in IEEEStd-519-1992, [9], for voltage harmonic distortions, varies according to the voltage class in the measured point. In this case, as the measurement points has a $380 \mathrm{~V}$ voltage level, the limit of total harmonic distortion of voltage $T H D_{v}$ should be $5.0 \%$ and the limit of the individual distortion should be $3.0 \%$.

\section{2) Repowering}

The Tab. II shows the operating conditions of the synchronous generator $S_{G}$ and the induction generator $I_{G}$ for experimental testing. The values of active, reactive and total power and power factor of the $S_{G}$ and $I_{G}$ were obtained in the measurement points and $M_{4}$ and $M_{3}$, respectively for loads $N_{L}$. The Tab. III present data of active, reactive and total power and power factor to the measuring point $M_{1}$ for the various configurations proposed to loads $N_{L}$.

Table II. Active, Reactive and Total Power and Power Factor in $S_{G}$ e $I_{G}$ for $N_{L}$.

\begin{tabular}{c|c|c|c|c}
\hline Operation & $\mathrm{P}(\mathrm{W})$ & $\mathrm{Q}(\mathrm{VAr})$ & $\mathrm{S}(\mathrm{VA})$ & $\mathrm{fp}$ \\
\hline$S_{G}$ & -1085 & $-3595 \mathrm{I}$ & 3767 & 0.291 \\
$\mathrm{I}_{\mathrm{G}}$ & -1007 & $3783 \mathrm{C}$ & 3767 & 0.256 \\
\hline
\end{tabular}

Table III. Active, Reactive and Total Power and Power Factor in $M_{1}$ for $N_{L}$.

\begin{tabular}{c|c|c|c|c}
\hline Configuration & $\mathrm{P}(\mathrm{W})$ & $\mathrm{Q}(\mathrm{VAr})$ & $\mathrm{S}(\mathrm{VA})$ & $\mathrm{fp}$ \\
\hline$N_{L}$ & 500 & $174.9 \mathrm{I}$ & 531.3 & 0.943
\end{tabular}

\begin{tabular}{c|c|c|c|c}
$S_{G}+N_{L}$ & -681 & $-3379 \mathrm{I}$ & 3454 & 0.2 \\
$S_{G}+I_{G}+N_{L}$ & -1644 & $818 \mathrm{C}$ & 1865 & 0.92 \\
$I_{G}+N_{L}$ & -514 & $3949 \mathrm{C}$ & 3995 & 0.133 \\
\hline
\end{tabular}

The Tab. III present the data powers in secondary side of the transformer for various configurations with two types of nonlinear load connected to the system. In the configuration where only $N_{L}$ is connected, the network is providing active power of $500 \mathrm{~W}$. With the synchronous generator connection, configuration $S_{G}+N_{L}$, the network is providing active power of $681 \mathrm{~W}$. Connecting the induction generator, setting $S_{G}+I_{G}+N_{L}$, the network is receiving active power of 1644 $\mathrm{W}$. Note that with the inclusion of the induction generator is repowering of the system. Note also that the power factor in $M_{1}$ the configuration $S_{G}+I_{G}+N_{L}$ is 0.92 .

\section{3) Harmonics}

The values shown in Tab. IV and Tab. V illustrate for a total harmonic distortion of voltage and for a total harmonic distortion of current to the measuring points $M_{1}, M_{2}, M_{3}$, $M_{4}$ and $M_{5}$, respectively.

By measuring $M_{1}$, presented in Tab. IV and Tab. $\mathrm{V}$ is observed that the value total harmonic distortion of voltage increases of $1.9 \%$ for $2.1 \%$ in the configuration $S_{G}+N_{L}$, and mitigates to $1.7 \%$ in $I_{G}+N_{L}$. In the setting $S_{G}+I_{G}+N_{L}$, mitigates the amount to $1.5 \%$. The total harmonic distortion of current generated for the setting $N_{L}$ in $M_{1}$ is $23.1 \%$. In setting $S_{G}+N_{L}$ mitigates the value to $4.6 \%$ and setting $I_{G}+$ $N_{L}$ mitigates the value to $5.6 \%$. In the setting $S_{G}+I_{G}+N_{L}$ mitigates the amount to $12.1 \%$. This proves that both the synchronous generator as induction generator mitigates the harmonic distortion in IEPS. In setting $S_{G}+I_{G}+N_{L}$ the value of $T H D_{i}$ is $2.8 \%$ in $M_{3}$ and $1.5 \%$ in $M_{4}$ and the value of $T H D_{v}$ is $1.5 \%$ in $M_{3}$ and $1.4 \%$ in $M_{4}$, showing that the induction generator behaves as a preferential path for harmonic.

Table IV. Values of $T H D v(\%)$ in $M_{1}, M_{2}, M_{3}$ e $M_{4}$ with $N_{L}$.

\begin{tabular}{c|c|c|c|c}
\hline & \multicolumn{4}{|c}{$T D H v$} \\
\hline Configuração & $M_{5}$ & $M_{1}$ & $M_{3}$ & $M_{4}$ \\
\hline CNL & 1.7 & 1.9 & - & - \\
SG+CNL & 1.7 & 2.1 & - & 2.0 \\
SG+IG+CNL & 1.6 & 1.5 & 1.5 & 1.4 \\
IG+CNL & 1.7 & 1.7 & 1.7 & - \\
\hline
\end{tabular}

Table V. Values of THDi (\%) in $M_{1}, M_{2}, M_{3}$ e $M_{4}$ with $N_{L}$.

\begin{tabular}{c|c|c|c|c}
\hline & \multicolumn{4}{|c}{$T D H i$} \\
\hline Configuração & $M_{5}$ & $M_{1}$ & $M_{3}$ & $M_{4}$ \\
\hline CNL & 17.8 & 23.1 & - & - \\
SG+CNL & 4.3 & 4.6 & - & 1.8 \\
SG+IG+CNL & 17.9 & 15.4 & 2.8 & 1.5 \\
IG+CNL & 5.5 & 5.6 & 3.3 & - \\
\hline
\end{tabular}

These results reaffirm the proposed use of induction generators to mitigate the harmonics in the main generators of power plants.

\section{B. Case Study 2}

1) Experimental Tests

Components and values of IEPS of Fig. 6 are reported in the 
Tab. VI, along with their values.

Table VI. Acronyms and Values of the Components from IEPS

\begin{tabular}{c|l|l}
\hline Variable & Components & Components Values of Used \\
\hline$S_{G}$ & $\begin{array}{l}\text { Synchronous Generator } \\
\text { (main generator) }\end{array}$ & $\begin{array}{l}37 \mathrm{kVA}, 380 \mathrm{~V}, \text { three-phase, } \\
\text { salient, 4poles, } 60 \mathrm{~Hz}\end{array}$ \\
$I_{G}$ & Induction Generator & $\begin{array}{l}7.5 \mathrm{kVA}, 380 \mathrm{~V}, \text { three-phase, cage } \\
\text { rotor, 4poles, } 60 \mathrm{~Hz}\end{array}$ \\
$N_{L}$ & $\begin{array}{l}\text { Nonlinear Load } \\
14 \mathrm{~kW} \text { three-phase, } 380 \mathrm{~V}, 60 \mathrm{~Hz}\end{array}$ \\
$S_{1}, S_{2}, S_{3}$ & Interrupter & \\
\hline
\end{tabular}

\section{2) Repowering}

The operating conditions of synchronous generator $S_{G}$ and induction generator $I_{G}$ for experimental testing are presented in Tab. VII. The values of active, reactive and total power and power factor were obtained in measurement points $M_{4}$ and $M_{3}$, for loads $N_{L}$. The Tab. VIII present data of active, reactive and total power and power factor to measuring point $M_{1}$ for various configurations proposed to loads $N_{L}$. The excitement of synchronous generator was tuned to get the best power factor $N_{L}$ on $S_{G}+I_{G}+N_{L}$ configuration.

Table VII. Active, Reactive and Total Power and Power Factor in $S_{G}$ e $I_{G}$ for $N_{L}$.

\begin{tabular}{c|c|c|c|c}
\hline Operation & $\mathrm{P}(\mathrm{W})$ & $\mathrm{Q}(\mathrm{VAr})$ & $\mathrm{S}(\mathrm{VA})$ & $\mathrm{fp}$ \\
\hline$S_{G}$ & -23003 & -7912 & 24343 & 0.945 \\
$\mathrm{I}_{\mathrm{G}}$ & -4011 & 4737 & 6214 & 0.645 \\
\hline
\end{tabular}

Table VIII. Active, Reactive and Total Power and Power Factor in $M_{1}$ for $N_{L}$.

\begin{tabular}{c|c|c|c|c}
\hline Configuration & $\mathrm{P}(\mathrm{W})$ & $\mathrm{Q}(\mathrm{VAr})$ & $\mathrm{S}(\mathrm{VA})$ & $\mathrm{fp}$ \\
\hline$N_{L}$ & 1452 & 2996 & 5713 & 0.254 \\
$S_{G}+N_{L}$ & -21682 & -4751 & 22699 & 0.955 \\
$S_{G}+I_{G}+N_{L}$ & -19847 & -553 & 22011 & 0.895 \\
$I_{G}+N_{L}$ & 2830 & 8985 & 13332 & 0.334 \\
\hline
\end{tabular}

The Tab. VIII presents the data powers in secondary side of the transformer for various configurations with types of nonlinear load connected to system. In the configuration where only $N_{L}$ is connected, the network is providing active power of $1452 \mathrm{~W}$. In $S_{G}+N_{L}$ configuration, with synchronous generator connection, that provides active power of $23003 \mathrm{~W}$, as Tab. VII. Network starts to receive active power of 21682 $\mathrm{W}$ in the case.

Connecting induction generator, setting $S_{G}+I_{G}+N_{L}$, the network is receiving active power of $19847 \mathrm{~W}$. In this case, has a load receiving $452 \mathrm{~W}$, synchronous generator providing $23003 \mathrm{~W}$, induction generator providing $4011 \mathrm{~W}$, as Tab. VII. The primary machine of induction generator, connected to $S_{3}$ key receive $5368 \mathrm{~W}$. Note that with induction generator inclusion, the system is repowering. Note also that the power factor in $M_{1}$ the configuration $S_{G}+I_{G}+N_{L}$ is 0.895 , this is due to the power factor of synchronous generator manufacturer that is 0.8 .

\section{3) Harmonics}

The values shown in Tab. IX and Tab. X illustrate for a total harmonic distortion of voltage and for a total harmonic distortion of current to measuring points $M_{1}, M_{2}, M_{3}$ and $M_{4}$. Table IX. Values of THDv (\%) in $M_{1}, M_{2}, M_{3} e M_{4}$ with $N_{L}$.

\begin{tabular}{c|c|c|c|c}
\hline & \multicolumn{4}{|c}{$T D H v$} \\
\hline Configuration & $M_{1}$ & $M_{2}$ & $M_{3}$ & $M_{4}$ \\
\hline $\mathrm{CNL}$ & 1.6 & 1.6 & - & - \\
$\mathrm{SG}+\mathrm{CNL}$ & 1.5 & 1.5 & - & - \\
$\mathrm{SG}+\mathrm{IG}+\mathrm{CNL}$ & 1.5 & 1.5 & 1.5 & 1.4
\end{tabular}

Table X. Values of THDi (\%) in $M_{1}, M_{2}, M_{3}$ e $M_{4}$ with $N_{L}$.

\begin{tabular}{c|c|c|c|c}
\hline & \multicolumn{4}{|c}{$T D H i$} \\
\hline Configuration & $M_{1}$ & $M_{2}$ & $M_{3}$ & $M_{4}$ \\
\hline CNL & 137.9 & 137.9 & - & - \\
SG+CNL & 21.9 & - & - & 3.4 \\
SG+IG+CNL & 41.9 & 137 & 3.7 & 3.4 \\
IG+CNL & 81.2 & 137.1 & 3.5 & - \\
\hline
\end{tabular}

By measuring $M_{1}$, presented in Tab. IX and Tab. $\mathrm{X}$ is observed that the value total harmonic distortion of voltage is $1.6 \%$ in $N_{L}$ configuration and mitigates to $1.5 \%$ in configurations $S_{G}+N_{L}, I_{G}+N_{L}$, and $S_{G}+I_{G}+N_{L}$. The total harmonic distortion of current generated for the $N_{L}$ setting in $M_{1}$ is $137.9 \%$. In setting $S_{G}+N_{L}$ mitigates the value to $21.9 \%$ and setting $I_{G}+N_{L}$ mitigates the value to $41.9 \%$. In the setting $S_{G}+I_{G}+N_{L}$ mitigates to $81.2 \%$. This proves that both synchronous and induction generator decrease the harmonic distortion in IEPS. In setting $S_{G}+I_{G}+N_{L}$ the value of $T H D_{i}$ is $3.7 \%$ in $M_{3}$ and $3.4 \%$ in $M_{4}$ and the value of $T H D_{v}$ is $1.5 \%$ in $M_{3}$ and $1.4 \%$ in $M_{4}$, showing that the induction generator behaves as a preferential path for harmonic.

These results reaffirm the proposed use of induction generators to repowering and attenuation the harmonics in the main generators of power plants.

The Fig. 8 shows the current waveform with non-linear load connected in system. The total harmonic distortion of voltage $T H D_{v}$ and current $T H D_{i}$ with nonlinear load connected to system was $1.6 \%$ and $137.9 \%$, respectively. All individual harmonics were significant with values above $18.1 \%$, individual harmonic values are shown in Tab. XI.

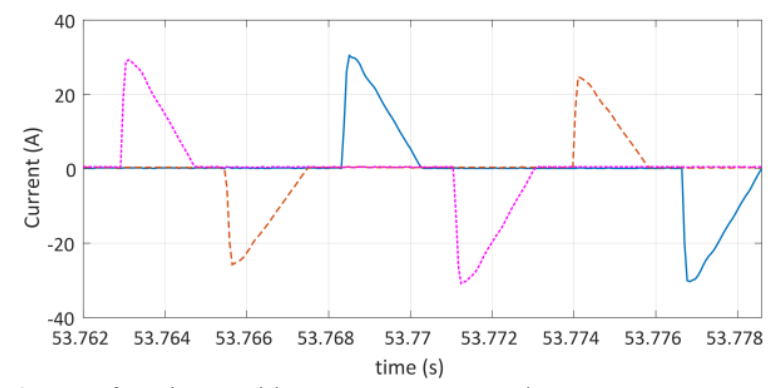

Fig. 8. Waveform in $M_{1}$ with $T H D_{i}-N_{L}$ connected.

Table XI. Values in $M_{1}$ with $T H D_{i}-N_{L}$ connected.

\begin{tabular}{|c|c|c|c|}
\hline$T H D_{v}$ & \multicolumn{2}{|l|}{$1.6 \%$} & \\
\hline$T H D_{i}$ & \multicolumn{3}{|c|}{$137.9 \%$} \\
\hline Harmonic & $\mathrm{AB}$ & $\mathrm{BC}$ & CA \\
\hline $60 \mathrm{~Hz}$ (Fnd)) & $100 \%$ & $100 \%$ & $100 \%$ \\
\hline $180 \mathrm{~Hz}^{\left(\mathrm{h}^{3}\right)}$ & $89.2 \%$ & $89.5 \%$ & $89.4 \%$ \\
\hline $300 \mathrm{~Hz}\left(\mathrm{~h}^{5}\right)$ & $70.0 \%$ & $70.2 \%$ & $70.8 \%$ \\
\hline $420 \mathrm{~Hz}\left(\mathrm{~h}^{7}\right)$ & $48.1 \%$ & $48.3 \%$ & $49.3 \%$ \\
\hline $540 \mathrm{~Hz}\left(\mathrm{~h}^{9}\right)$ & $29.9 \%$ & $30.2 \%$ & $30.6 \%$ \\
\hline $660 \mathrm{~Hz}\left(\mathrm{~h}^{11}\right)$ & $21.4 \%$ & $21.1 \%$ & $20.7 \%$ \\
\hline $780 \mathrm{~Hz}\left(\mathrm{~h}^{13}\right)$ & $20.7 \%$ & $19.9 \%$ & $19.1 \%$ \\
\hline $900 \mathrm{~Hz}\left(\mathrm{~h}^{15}\right)$ & $19.5 \%$ & $18.8 \%$ & $18.1 \%$ \\
\hline
\end{tabular}

The Fig. 9 shows the current waveform, after entry of synchronous generator with non-linear load connected to system. The total harmonic distortion of voltage $T H D_{v}$ and current $T H D_{i}$ after synchronous generator switching with a nonlinear load connected was $1.5 \%$ and $21.9 \%$, respectively. 
The total harmonic distortion of current $T H D_{i}$ attenuated from $137.9 \%$ to $21.9 \%$ and the most significant individual harmonic orders were the third order $h_{3}$ an attenuation from $89.5 \%$ to $14.1 \%$ and fifth order $h_{5}$ with an attenuation from $70.8 \%$ to $13.4 \%$, the values of the other harmonics are listed in Tab. XII. The reduction is due to the fact that the synchronous generator is overexcited in order to supply reactive induction generator, while maintaining the power factor as close to 0.92 in $M_{1}$, when the configuration $S_{G}+I_{G}+N_{L}$.

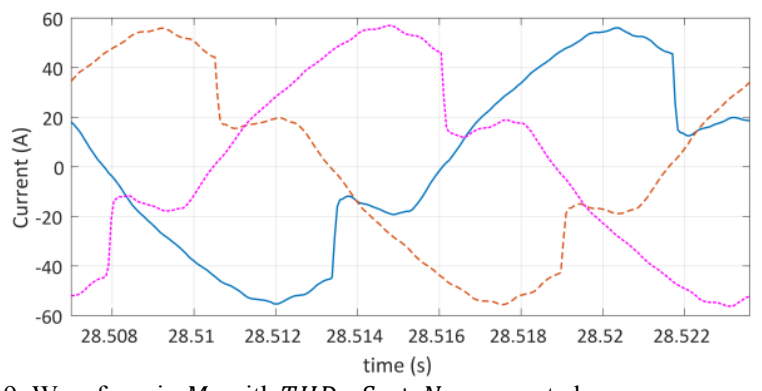

Fig. 9. Waveform in $M_{1}$ with $T H D_{i}-S_{G}+N_{L}$ connected.

Table XII. Values in $M_{1}$ with $T H D_{i}-S_{G}+N_{L}$ connected.

\begin{tabular}{c|l|l|l}
\hline \multicolumn{1}{c|}{$T H D_{v}$} & \multicolumn{1}{l}{$1.5 \%$} & \multicolumn{2}{l}{} \\
\hline$T H D_{i}$ & $21.9 \%$ & CA \\
\hline Harmonic & AB & BC & CB \\
\hline $60 \mathrm{~Hz}($ Fnd $))$ & $100 \%$ & $100 \%$ & $100 \%$ \\
$180 \mathrm{~Hz}\left(\mathrm{~h}^{3}\right)$ & $13.7 \%$ & $13.0 \%$ & $14.1 \%$ \\
$300 \mathrm{~Hz}\left(\mathrm{~h}^{5}\right)$ & $13.4 \%$ & $11.4 \%$ & $13.0 \%$ \\
$420 \mathrm{~Hz}\left(\mathrm{~h}^{7}\right)$ & $8.3 \%$ & $6.5 \%$ & $8.3 \%$ \\
$540 \mathrm{~Hz}\left(\mathrm{~h}^{9}\right)$ & $5.0 \%$ & $3.9 \%$ & $4.7 \%$ \\
$660 \mathrm{~Hz}\left(\mathrm{~h}^{11}\right)$ & $3.6 \%$ & $2.7 \%$ & $3.4 \%$ \\
$780 \mathrm{~Hz}\left(\mathrm{~h}^{13}\right)$ & $3.0 \%$ & $2.1 \%$ & $2.7 \%$ \\
$900 \mathrm{~Hz}\left(\mathrm{~h}^{15}\right)$ & $3.2 \%$ & $2.3 \%$ & $2.9 \%$ \\
\hline
\end{tabular}

The Fig. 10 shows the current waveform, after induction generator input with synchronous generator and non-linear load connected to system. The total harmonic distortion of voltage $T H D_{v}$ and current $T H D_{i}$ after induction generator switching with a synchronous generator and a nonlinear load connected was $1.5 \%$ and $41.9 \%$, respectively. The total harmonic distortion of current $T H D_{i}$ increased from $21.9 \%$ to $41.9 \%$ and the most significant individual harmonic orders were the third order $h_{3}$ an increment from $14.1 \%$ to $45.6 \%$ and fifth order $h_{5}$ with an increment from $13.4 \%$ to $38.3 \%$. The values of the other harmonics are listed in Tab. XIII. The purpose of this configuration is to keep the power factor as close to 0.92 in $M_{1}$, which means that there is reduction of harmonics in relation to the configuration $N_{L}$, but increase over the $S_{G}+N_{L}$.

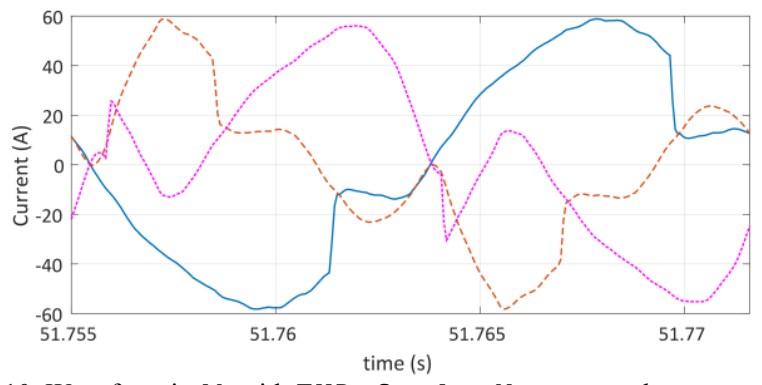

Fig. 10. Waveform in $M_{1}$ with $T H D_{i^{-}} S_{G}+I_{G}+N_{L}$ connected.

Table XIII. Values in $M_{1}$ with $T H D_{i}-S_{G}+I_{G}+N_{L}$ connected.

\begin{tabular}{l|l|l|l}
\hline \multicolumn{1}{c|}{$T H D_{v}$} & \multicolumn{2}{l}{$1.5 \%$} & \multicolumn{2}{l}{} \\
\cline { 1 - 2 }$T H D_{i}$ & $41.9 \%$ & \multicolumn{1}{l}{} \\
\cline { 1 - 2 } Harmonic & AB & BC & CA \\
\hline $60 \mathrm{~Hz}($ Fnd)) & $100 \%$ & $100 \%$ & $100 \%$ \\
$180 \mathrm{~Hz}\left(\mathrm{~h}^{3}\right)$ & $12.2 \%$ & $35.3 \%$ & $45.6 \%$ \\
$300 \mathrm{~Hz}\left(\mathrm{~h}^{5}\right)$ & $12.1 \%$ & $38.3 \%$ & $27.5 \%$ \\
$420 \mathrm{~Hz}\left(\mathrm{~h}^{7}\right)$ & $7.4 \%$ & $0.6 \%$ & $9.3 \%$ \\
$540 \mathrm{~Hz}\left(\mathrm{~h}^{9}\right)$ & $4.3 \%$ & $8.3 \%$ & $4.1 \%$ \\
$660 \mathrm{~Hz}\left(\mathrm{~h}^{11}\right)$ & $3.1 \%$ & $3.5 \%$ & $1.4 \%$ \\
$780 \mathrm{~Hz}\left(\mathrm{~h}^{13}\right)$ & $2.7 \%$ & $2.2 \%$ & $1.0 \%$ \\
$900 \mathrm{~Hz}\left(\mathrm{~h}^{15}\right)$ & $2.8 \%$ & $5.3 \%$ & $1.6 \%$ \\
\hline
\end{tabular}

The Fig. 11 shows the current waveform, after entry of induction generator with non-linear load connected to system. The total harmonic distortion of voltage $T H D_{v}$ and current $T H D_{i}$ after synchonous generator swiching off, with the induction generator and a nonlinear load connected to system was $1.5 \%$ and $81.2 \%$, respectively. The total harmonic distortion of current $T H D_{i}$ attenuated from $137.9 \%$ to $81.2 \%$ and the most significant individual harmonic orders were the third order $h_{3}$ an attenuation from $89.5 \%$ to $83.0 \%$ and fifth order $h_{5}$ with an increment from $70.8 \%$ to $76.6 \%$, the values of the other harmonics are listed in Tab. XIV. It shows a decrease with respect to $N_{L}$ configuration, but it is important to note that with induction generator connection there feeding of primary machine that increases distortion at $M_{3}$ measuring point. Furthermore, the induction generator is a smaller machine than the synchronous one.

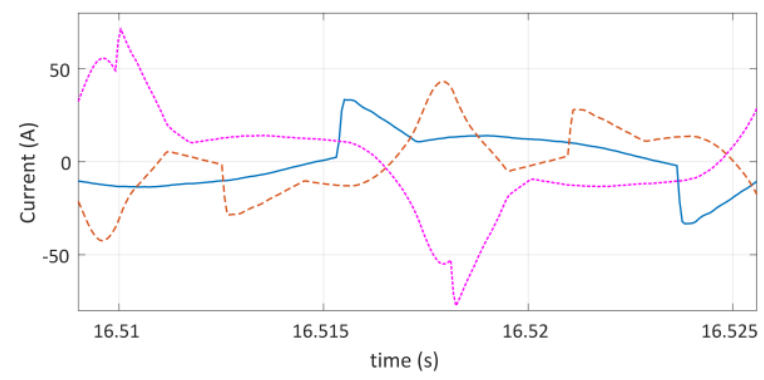

Fig. 11. Waveform in $M_{1}$ with $T H D_{i}-I_{G}+N_{L}$ connected.

Table XIV. Values in $M_{1}$ with $T H D_{i}-I_{G}+N_{L}$ connected.

\begin{tabular}{l|l|l|l}
\hline \multicolumn{1}{c|}{$T H D_{v}$} & \multicolumn{1}{l}{$1.5 \%$} & \multicolumn{2}{l}{} \\
\cline { 1 - 3 }$T H D_{i}$ & $81.2 \%$ & \multicolumn{1}{l}{} \\
\hline Harmonic & AB & BC & CA \\
\hline $60 \mathrm{~Hz}($ Fnd $))$ & $100 \%$ & $100 \%$ & $100 \%$ \\
$180 \mathrm{~Hz}\left(\mathrm{~h}^{3}\right)$ & $37.6 \%$ & $83.0 \%$ & $61.1 \%$ \\
$300 \mathrm{~Hz}\left(\mathrm{~h}^{5}\right)$ & $29.4 \%$ & $76.6 \%$ & $30.5 \%$ \\
$420 \mathrm{~Hz}\left(\mathrm{~h}^{7}\right)$ & $20.7 \%$ & $5.8 \%$ & $10.1 \%$ \\
$540 \mathrm{~Hz}\left(\mathrm{~h}^{9}\right)$ & $12.6 \%$ & $20.6 \%$ & $3.5 \%$ \\
$660 \mathrm{~Hz}\left(\mathrm{~h}^{11}\right)$ & $9.1 \%$ & $9.1 \%$ & $1.0 \%$ \\
$780 \mathrm{~Hz}\left(\mathrm{~h}^{13}\right)$ & $8.8 \%$ & $6.8 \%$ & $1.2 \%$ \\
$900 \mathrm{~Hz}\left(\mathrm{~h}^{15}\right)$ & $8.3 \%$ & $11.8 \%$ & $2.1 \%$ \\
\hline
\end{tabular}

The individual harmonic distortion of current generated at $M_{1}$ is higher than $N_{L}$ configuration. Both for $S_{G}+N_{L}$ setting as for $S_{G}+N_{L}$ there is an attenuation in individual distortions, to be more significant in configuration $S_{G}+N_{L}$.

It is necessary to conduct a detailed analysis $S_{G}+N_{L}$ and $I_{G}+N_{L}$ configurations, where it is important to consider that: i) the synchronous generator is configured to supply the reactive induction generator keeping the power factor as 0.92 in $M_{1}$, which makes work in the region where shows attenuation characteristic of harmonics; ii) at $M_{3}$ measuring 
point is included the induction generator and the primary machine, increasing total harmonic distortion of this configuration, since the primary machine still has power biphasic and iii) the induction generator is active power machine approximately five times smaller than synchronous one.

\section{CONCLUSIONS}

This work confirmed through the results that induction generator in connection with a synchronous generator and a nonlinear load has the ability, to increase the power generated, available for the electrical system, besides increasing the power generation available for the electrical system, attenuating harmonic distortion current and voltage in commom bus. The induction machine besides showing low cost, robustness, simple construction, lower cost and less maintenance compared with synchronous machine, repowering the system. The results showed that harmonic distortion bus suffers reductions for synchronous generator connection as for induction generator connection. It is noted in results that induction generator provided a preferred path for current harmonic order, even when two machines produce or consume equivalent and proportional reactive power.

\section{ACKNOWLEDGMENT}

The authors would like to thank Coordination for the Improvement of Higher Education Personnel (CAPES), the National Counsel of Technological and Scientific Development (CNPq) and the Research Support Foundation of Goias State (FAPEG) for financial support research and scholarships.

\section{REFERENCES}

[1] J. M. Chapallaz; J. D. Ghali; P. Eichenberger and G. Fischer. "Manual on Motors Used as Generators". MHPG Series, Vol. 10, Friedr. Vieweg \& Sohn Verlagsgesellschaft mbH, Germany.

[2] D. M. Medeiros. "The use of pumps operating as turbines and induction generators to generate electricity". Thesis in Portuguese, Federal University of Itajubá, Itajubá, Minas Gerais, Brazil, 2004.

[3] K. D Pham. "Cogeneration Application: Interconnection of Induction Generators with public Eletric Utility". Rural Electric Power Conference - REPC, 1991.

[4] V, Pongpornsup. "Impacts of Non-Utility Induction Generator to Distribution Network". IEEE Transmission and Distribution Conference and Exhibition, Vol. 2, Pages 1352-1356, 2002.

[5] R. Behome; M. Plamondon, H. Nakra, D. Desrosiers, C. Gagnon. "Case Study on the Integration of a Non-Utility Induction Generator to the Hydro-Quebec Distribution Network". IEEE Transactions on Power Delivery, Vol. 10, No. 3, 1995.

[6] J.A. Laghari, H. Mokhlis, A. H. A. Bakar, M. Hasmaini, "A comprehensive overview of new designs in the hydraulic, electrical equipments and controllers of mini hydro power plants making it cost effective technology". Renewable and Sustainable Energy Reviews, Vol. 20, Pages 279-293, 2013.

[7] N. Sivakumar, DAS. Devadutta, PADHY, N.P. Padhy. "Variable speed operation of reversible pump-turbines at Kadamparai pumped storage plant - A case study". Elsevier Energy Conversion and Management, Pages 96 - 104, 2014.

[8] P.J. Reddy, S.P. Singh, "Voltage and Frequency Control of Parallel Operated Synchronous and Induction Generators in Micro Hydro scheme". Computation of Power, Energy, Information and Communication (ICCPEIC), Vol. 1, Pages 124 - 129, 2014.
[9] IEEE STD 519-1992. "IEEE Recommended Practices and Requirements for Harmonic Control in Electrical Power Systems". New York, 1993.

[10] R. L. Nailen. "Spooks on the Power Line? Induction Generators and the Public Utility". IEEE Transaction on Industry Applications, Vol. 1A-18, No. 6, 1982.

[11] A. S. Magalhães; L. C. A. Junior; C. A. Matias; A. H. F. Silva; E. G. Domingues; A. J. Alves and W. P. Calixto. "Repowering of a Synchronous Generation Plant by Induction Generator." IEEE Congreso Chileno de Ingeniería Eléctrica, Electrónica, Tecnologías de la Información y Comunicaciones (IEEE CHILECON 2015), 2015, Santiago.

[12] E. Delbone. " Harmonic Attenuation in the Synchronous Generator due the Nonlinear Loads Using Induction Generators". Thesis in Portuguese, Federal University of Uberlandia, Uberlandia, Minas Gerais, Brazil, 2012.

[13] R. Behome; M. Plamondon, H. Nakra, D. Desrosiers, C. Gagnon. " Steam Power Plant Re-powering to provide Black-Start Ancillary Service and speed up Power System Restoration". IEEE Bologna PowerTech Conference, 2003.

[14] A. Gaglianoa, G. M. Tinab, F. Noceraa , F. Patania. " Technical and Economic Perspective for Repowering of Micro Hydro Power Plants: a Case Study of an Early XX Century Power Plant". Energy Procedia, 6th International Conference on Sustainability in Energy and Buildings, SEB-14, 2014. 